\title{
Spinocerebellar ataxia-dysmorphism syndrome
}

INSERM

\section{Source}

INSERM. (1999). Orphanet: an online rare disease and orphan drug data base.

Spinocerebellar ataxia-dysmorphism syndrome. ORPHA:1185

Spinocerebellar ataxia-dysmorphism is marked by characteristic facies associated with dysarthria, delayed psychomotor development, ataxia, scoliosis and foot deformities.

Three cases have been described and transmission appears to be autosomal recessive. 